\title{
Recent Advances in the Diagnosis and Treatment of Pheochromocytoma
}

\author{
Jiri Widimský, Jr. \\ Center for Hypertension, Charles University, Third Internal Department, Prague, Czech Republic
}

\section{Key Words}

Pheochromocytoma - Pheochromocytoma, blood pressure - Pheochromocytoma, diagnosis and treatment • Pheochromocytoma, genetic analysis

\begin{abstract}
Pheochromocytoma (PHEO) is considered to be a rare cause of hypertension. However, if left untreated, PHEOs may lead to fatal hypertensive crises during anesthesia and other stresses. The diagnosis of PHEO is therefore extremely important. A 24-hour blood pressure (BP) pattern per se might be of some diagnostic value due to frequently observed higher BP variability as well as an attenuated night-time BP decrease. So far, germline mutations in five genes have been identified to be responsible for familial PHEOs: the von Hippel-Lindau gene, which causes von Hippel-Lindau syndrome, the RET gene leading to multiple endocrine neoplasia type 2 , the neurofibromatosis type 1 gene, which is associated with von Recklinghausen's disease and the genes encoding the $B$ and D subunits of mitochondrial succinate dehydrogenase $(\mathrm{SDHB}$, SDHD), which are associated with familial paragangliomas and PHEOs. Genetic analysis should be offered to those patients with confirmed PHEO who are 50 years old or younger. Plasma-free metanephrines or urinary fractionated metanephrines seem to have higher diagnostic values compared to plasma or urinary catecholamines for the biochemical diagnosis of PHEO. Imaging with ${ }^{123}$-metaiodobenzylguani-
\end{abstract}

This invited review was supported by the unrestricted educational grant provided by Amgen.

\section{KARGER \\ Fax +41613061234 E-Mail karger@karger.ch} www.karger.com
(C) 2006 S. Karger AG, Basel

$1420-4096 / 06 / 0295-0321 \$ 23.50 / 0$

Accessible online at:

www.karger.com/kbr dine or ${ }^{18} \mathrm{~F}$-fluorodopamine PET, if available, are in addition to CT/MRI useful for the detection of multifocal/extra-adrenal forms. Appropriate pharmacologic treatment with subsequent laparoscopic extirpation of PHEO is usually successful in benign forms. There is, however, no convincingly effective mode of treatment in malignant PHEOs.

Copyright $\odot 2006$ S. Karger AG, Basel

\section{Prevalence}

Pheochromocytoma (PHEO) is considered to be a rare cause of hypertension. Large studies on autopsies in Sydney, Melbourne and Auckland indicated only 1 case found per 2,031 autopsies [1]. Prevalence estimates for PHEO vary from 0.01 to $0.1 \%$ of the hypertensive population. Not surprisingly, these figures are considerably higher in specialized hypertensive centers [2]. Although PHEOs are relatively rare, diagnosis and treatment are extremely important. If left untreated, PHEOs may lead to fatal hypertensive crises during anesthesia and other stresses [3]. This notion is further emphasized by the fact that approximately $10 \%$ of all PHEOs are found incidentally and about $5 \%$ of all incidentalomas are PHEOs [4].

\section{Blood Pressure Characteristics}

Sustained hypertension is more common than paroxysmal hypertension. Patients with sustained hypertension may however have superimposed paroxysms of hy-

J. Widimský, Jr.

Center for Hypertension, Charles University

Third Internal Department

Unemocnice 1, Prague 2 (Czech Republic)

E-Mail jwidi@lf1.cuni.cz 
Table 1. Clinical characteristics of genes associated with familial forms of PHEO (modified from Lenders et al. [10])

\begin{tabular}{llllll}
\hline Type of mutation & VHL & RET & SDHB & SDHD & NF1 \\
\hline $\begin{array}{l}\text { Frequency } \\
\quad \text { \% of sporadic PHEO }\end{array}$ & $2-20$ & $<5$ & $3-10$ & $4-7$ & 1 \\
$\quad \%$ of malignant disease & 5 & 3 & 50 & $<3$ & 11 \\
$\begin{array}{l}\text { Localization } \\
\quad \text { Adrenal }\end{array}$ & ++ & ++ & + & + & ++ \\
$\quad$ Extra-adrenal & + & - & ++ & ++ & + \\
\hline
\end{tabular}

pertension that can be brought on in multiple ways like exercise, anesthesia, smoking, urination, defecation, or induction of the pressure on the abdomen.

It is believed that patients with PHEO present more frequently with hypertension resistant to drug therapy. Although episodes of catecholamine release may sometimes lead to blood pressure (BP) $>250 / 150 \mathrm{~mm} \mathrm{Hg}$, the 24-hour BP mean is usually lower compared to other forms of endocrine hypertension like primary aldosteronism or Cushing's syndrome or in comparison with essential hypertension [5]. In most patients with PHEO, true resistance to the antihypertensive therapy is rare.

Circadian BP variation in PHEO is blunted with the absence of decrease or even increase in nocturnal BP [5]. This BP pattern evaluated by ambulatory 24-hour BP monitoring may be considered as a diagnostic clue, since no such profound BP circadian rhythm changes were noted in other forms of endocrine hypertension [5]. Normotension in PHEO may be observed in completely asymptomatic patients [6], the absence of high BP can be explained by the desensitization of the cardiovascular system due to high catecholamine levels. Interestingly, these normotensive individuals also have an attenuated night-time BP decline [6].

Catecholamines are responsible for short- and longlasting BP elevations. BP variability can be helpful in evaluating the risk of the hypertensive subjects since higher BP variability has been shown to correlate independently of other known risk factors with a higher incidence of cardiovascular morbidity and mortality [7]. The excess of catecholamines in patients with $\mathrm{PHEO}$ is associated with higher long-term $\mathrm{BP}$ variability in comparison with patients suffering from essential hypertension. This phenomenon is especially marked in subjects with inverted circadian BP rhythm [8]. Successful removal of the tumor results in the amelioration of the previously increased BP variability [8].
Ambulatory 24-hour BP monitoring may thus be helpful in the diagnosis of PHEO due to amelioration of the 24-hour BP rhythm and increase of BP variability.

\section{Familial Syndromes/Genetic Testing}

Familial PHEO is estimated to make up $10 \%$ of all PHEOs. A recent study performed mainly in Central Europe on a large sample of apparently sporadic PHEOs revealed a surprisingly relatively high (24\%) prevalence of germline mutations in one of four susceptibility genes for PHEO [9]. So far, germline mutations in five genes have been identified to be responsible for familial PHEOs (table 1): the von Hippel-Lindau (VHL) gene, which causes VHL syndrome, the RET gene leading to multiple endocrine neoplasia type 2, the neurofibromatosis type 1 gene (NF1), which is associated with von Recklinghausen's disease and the genes encoding the $\mathrm{B}$ and $\mathrm{D}$ subunits of mitochondrial succinate dehydrogenase (SDHB, SDHD), which are associated with familial paragangliomas and PHEOs $[10,11]$. As indicated in table 1 , PHEOs are not always present and usually are also not the first clinical manifestation of syndromes due to mutations of VHL, RET and NF1 genes [10].

It thus seems that the genetic analysis should be offered to those patients with confirmed PHEO, who are 50 years old or younger [10]. It also appears reasonable that all positive cases should be followed up throughout life. However, if genetic testing is negative in a family member of a patient with a hereditary form of PHEO, no other laboratory tests are indicated.

\section{Von Hippel-Lindau Syndrome}

Clinical manifestations can differ with two broad types (1 and 2) with a large diversity of features. PHEOs can only be part of VHL syndrome type 2, which may be subdivided into form $2 \mathrm{~A}$ presenting with retinal and CNS hemangioblastomas, PHEOs, endolymphatic sac tumors and epididymal cystadenomas. In addition to PHEO renal cell cysts and carcinomas, VHL syndrome type 2B may include retinal and CNS hemangioblastomas, pancreatic neoplasms and cysts, endolymphatic sac tumors and epididymal cystadenomas. The latter type (2C) presents with PHEO only [10].

\section{Multiple Endocrine Neoplasia Type 2}

This syndrome (mutation of RET gene) can vary with two main types: type A may also include medullary thyroid carcinoma, PHEO, hyperparathyroidism, cutaneous 
lichen amyloidosis or familial medullary thyroid carcinoma only (FMTC), and type B presents with medullary thyroid carcinoma, PHEO, multiple neuromas and marfanoid habitus [10].

\section{Paraganglioma Syndromes}

Paraganglioma syndromes include a diversity of clinical features like head and neck tumors (carotid body tumors, vagal, jugular and tympanic paragangliomas), and PHEO or abdominal and thoracic paragangliomas (or both). Head and neck paragangliomas are more commonly associated with SDHD mutations and are usually benign, while SDHB mutations are associated with an increased rate of malignant disease (80\%!) [11].

\section{Neurofibromatosis Type 1 Syndrome}

This syndrome may present with multiple fibromas on skin and mucosae, café-au-lait skin spots and PHEO. $\mathrm{PHEO}$ in this syndrome is very rare $(<5 \%)$ and thus diagnostic screening for PHEO is not generally indicated [10].

\section{Biochemical Diagnosis}

Significant technical progress has been made over the past 10 years. Eisenhofer et al. [12] indicated the greater sensitivity and specificity for assays of plasma metanephrines that can be explained by the differences in the affinity of catecholamines to membrane-bound catecholO-methyltransferase (COMT) in adrenal chromaffin cells. The affinity is much higher compared to COMT present elsewhere. All tumors metabolize amines to free metanephrine, but not all tumors secrete catecholamines $[4,12]$. While levels of catecholamines are increased by minimal anxiety and stress, levels of metanephrines are much less affected.

A multicentric cohort study performed on 214 patients with confirmed PHEOs in four different centers indicated that the test with free metanephrines in plasma is the best and should be used as a test of choice [13]. In a recent review of same authors the measurements of plasma-free metanephrines or urinary-fractioned metanephrines (normetanephrine and metanephrine separately) was considered as the most sensitive tests for diagnosis or reliable exclusion of PHEO [10]. Table 2 demonstrates sensitivity and specificity of different biochemical tests for the diagnosis of PHEO (according Lenders et al. [13]).

Despite a very high sensitivity of plasma/urinary metanephrines, the problems could be related to a rela-
Table 2. Sensitivity and specificity of biochemical tests for diagnosis of PHEO (from Lenders et al. [10])

\begin{tabular}{lll}
\hline & Sensitivity & Specificity \\
\hline Plasma-free metanephrines & $99 \%$ & $89 \%$ \\
Plasma catecholamines & $84 \%$ & $81 \%$ \\
Urinary catecholamines & $86 \%$ & $88 \%$ \\
Urinary fractionated metanephrines & $97 \%$ & $69 \%$ \\
Urinary total metanephrines & $77 \%$ & $93 \%$ \\
Vanillylmandelic acid & $64 \%$ & $95 \%$ \\
\hline
\end{tabular}

Specificity values for familial PHEO are higher compared to sporadic cases.

tively lower specificity and thus positive results do not always reliably confirm PHEO $[4,10]$. In addition to that, several drugs may interfere with the biochemical tests for PHEOs and thus lead to false-positive results. The most frequent interfering medication seems to be phenoxybenzamine or tricyclic antidepressants [14]. False-positive results may also be caused by dietary influences and/ or inappropriate sampling conditions.

Other investigators [15] recommend multiple tests be performed due to variable catecholamine metabolism. Combination of resting plasma norepinephrine + epinephrine $>2,000 \mathrm{pg} / \mathrm{ml}$ and urinary metanephrine $(\mathrm{MNM}+\mathrm{NM})>1.8 \mathrm{mg} / 24 \mathrm{~h}$ provided a diagnostic accuracy of $98 \%$ in both sporadic and familial PHEOs [15]. Obviously, the issue of costs should also be considered when a combination of tests is used.

Mayo Clinic researchers advocate an approach based on the probability of the presence of PHEO [16]. To minimize the number of false-positive cases, they recommend 24-hour urinary metanephrines and catecholamines. If the clinical suspicion is higher (suggestive symptoms, family history of PHEO, familial syndrome, adrenal mass) the tests with higher sensitivity, e.g. fractionated plasma-free metanephrines, should be preferred [16].

Urinary vanillylmandelic acid (VMA) determination is still being frequently used, however these assays have a lower sensitivity since approximately $80 \%$ of all VMA comes from metabolites of norepinephrine from sympathetic neurons and thus an increase of VMA excretion requires very high plasma catecholamines and metanephrines levels [4]. Thus, although uncertainty still exists about which test is definitely the best [4], plasma-free metanephrines or urinary fractionated metanephrines seem to be the appropriate choice $[10,13]$. 


\section{Pharmacologic Tests}

The clonidine test is the most widely pharmacologic approach used to differentiate between increased catecholamine release due to sympathetic activation from increased release due to PHEO [17]. If positive, this test is highly predictive for $\mathrm{PHEO}$ by $97 \%$. The negative predictive value is however relatively poor (75\%). Investigators from the NIH therefore recommend the clonidine suppression test with the measurement of plasma normetanephrine instead of plasma norepinephrine [18]. The positive and negative predictive value of this modification improved to 100 and $96 \%$ respectively [18]. This test thus seems to be the most accurate in the diagnosis of PHEO and is indicated in equivocal cases. Provocative tests (stimulation with histamine or glucagon) cause discomfort and are potentially hazardous, and due to the availability of other accurate tests have a minimal/questionable additional diagnostic value [4].

\section{Morphological Diagnostic Approaches}

Abdominal CT scans are often used for tumor localization. Evidence from one small study indicates that contrast enhancement with iohexol has no effect on plasma catecholamines [19]. $\mathrm{T}_{2}$-weighted MRI with gadolinium enhancement has a comparable diagnostic accuracy with CT scans $[4,10]$, but it is preferred for the localization of extra-adrenal tumors or tumors during pregnan$c y$, in children, in allergies to contrast or in renal insufficiency. No adrenergic blockade is needed in MRI.

Imaging with ${ }^{123}$ I-metaiodobenzylguanidine (MIBG) rather than ${ }^{131}$ I-MIBG, which has poorer quality, is indicated in patients with extra-adrenal or large $(>5 \mathrm{~cm})$ adrenal tumors with increased risk of malignant disease, or in patients with high suspicion of the presence of multifocal disease [10]. It is important to note that several drugs (labetalol, tricyclic antidepressants, calcium antagonists) may interfere with the uptake or retention of ${ }^{123} \mathrm{I}$-MIBG. If ${ }^{123}$ I-MIBG scans are negative, ${ }^{111}$ In-octreotide scan or PET with ${ }^{18} \mathrm{~F}$-fluorodeoxyglucose can be used. Both of these tests are non-specific for PHEO and thus are not recommended for initial diagnostic localization. ${ }^{18} \mathrm{~F}$ fluorodopamine PET has a better diagnostic sensitivity than MIBG scintigraphy [20], especially in metastatic PHEOs. ${ }^{18} \mathrm{~F}$-fluorodopamine (and other substances with similar properties like ${ }^{18} \mathrm{~F}$-fluorodopa and ${ }^{11} \mathrm{C}-$ hydroxyephedrine) is, however, not widely available. An algorithm for diagnostic localization of PHEO is depicted in figure 1 (according Ilias and Pacák [21]).

\section{Treatment}

\section{Benign PHEO}

Preoperative Pharmacologic Treatment. Preoperative pharmacologic treatment is necessary to reduce the risk and complications of surgery, since emergency tumor resection leads to poor survival [10]. Medical therapy consists of selective $\alpha_{1}$-blockers like doxazosin, terazosin or prazosin. Prazosin has the disadvantage of shorter duration of action. Phenoxybenzamine as non-selective, noncompetitive $\alpha$-blocking agent is also used, but this drug is not widely available. There are no randomized clinical trials comparing phenoxybenzamine with prazosin or doxazosin. Labetalol is less suitable for the preoperative management due to prevailing blockade of $\beta$-adrenoceptors compared to $\alpha$-blockade.

$\beta$-Blockers can be given to control tachycardia and arrhythmias, but only at least $24 \mathrm{~h}$ after therapy with $\alpha$ blockers has been initiated. If $\beta$-blockers are used alone, they may cause a pressor response or even pulmonary edema due to unopposed $\alpha$-receptor-mediated vasoconstriction, or removal by $\beta$-adrenergic drive to the heart, respectively [4].

Calcium channel blockers have also been used to inhibit catecholamine-mediated release of intracellular calcium alone or in combination with $\alpha$-blockers $[4,10]$. Although calcium channel blockers do not cause orthostatic hypotension, they do not completely prevent BP surges if used alone [10].

Pretreatment with $\alpha$-blockers, and potentially $\beta$ blockers, should be initiated at least 1 week, but preferably 10-14 days before surgery. The type of anesthetic agent seems to be of secondary importance [22] to control BP during surgery. If a substantial BP surge occurs during operation, administration of isosorbide dinitrate, sodium nitroprusside or a short-acting calcium antagonist is indicated. Short-acting $\beta$-blockers (esmolol) can also be used to treat tachyarrhythmias.

The risk of postoperative hypotension can be minimized by the increase of salt and fluid intake. Postoperative hypoglycemia may also occur due to sudden hyperinsulinemia.

Surgical Treatment. Due to accurate localization of the tumor and technical advances, laparoscopic removal of the tumor is now the widely used [23]. Compared to the conventional approach with upper abdominal incision, the laparoscopic technique decreases postoperative morbidity, hospital stay and expenses [23, 24]. In case of bilateral PHEOs, adrenal-cortex-sparing laparoscopic surgery has been recommended to prevent long-life gluco- 
Fig. 1. Algorithm for the diagnosis of PHEO (from Ilias and Pacák [21]). Positive $\mathrm{T}_{2^{-}}$or negative $\mathrm{T}_{2}$-weighted MRI examinations. $+=$ Examination positive for tumor; - = examination negative for tumor.

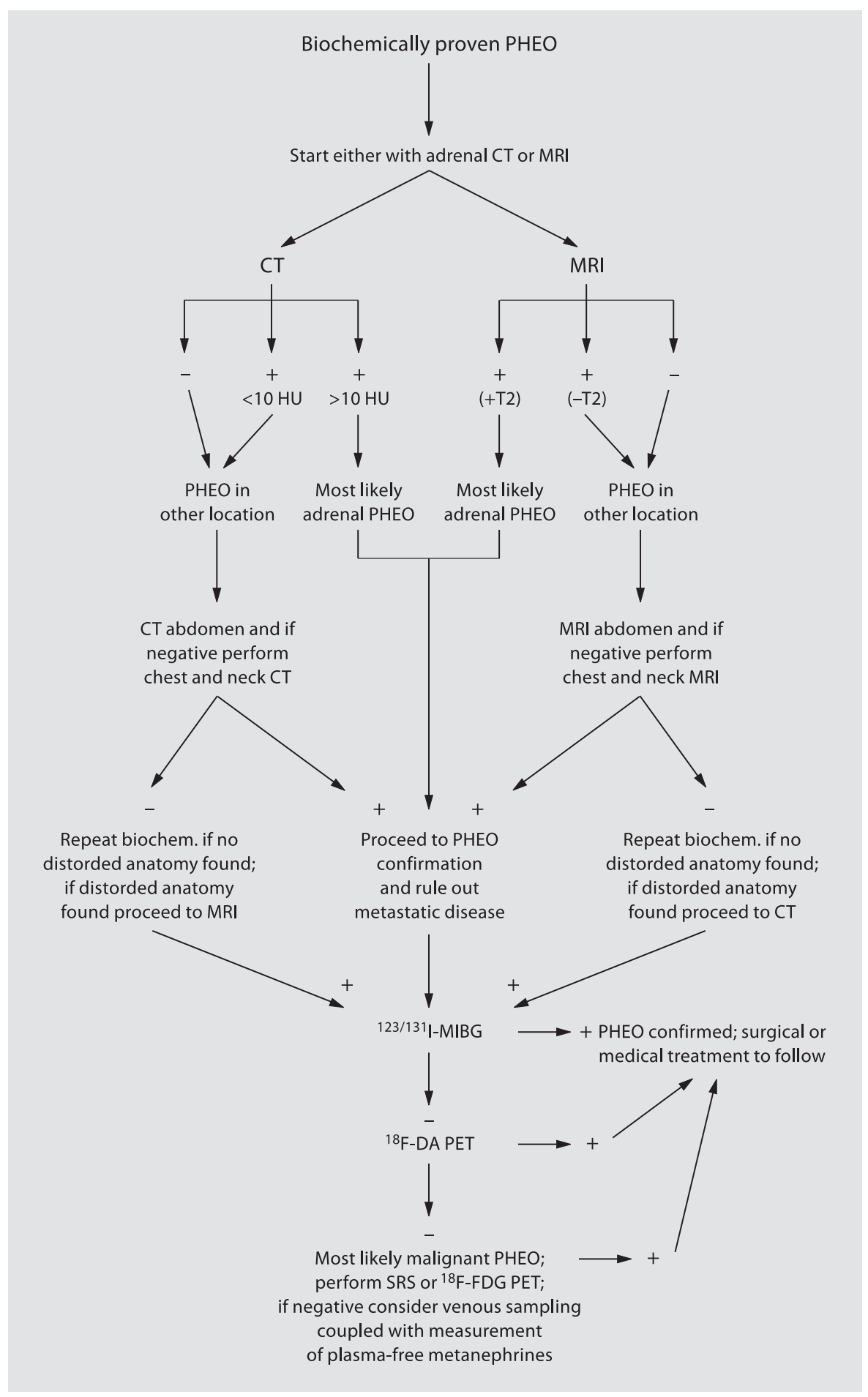

corticoid substitution. The prognosis of the patients after surgery is very good, but hypertension may persist (usually less severe) in nearly $50 \%$ of patients according some authors [25]. Long-term follow-up at regular intervals af- ter the operation is indicated since the recurrence rate of PHEO is $17 \%$ [25]. Recurrences are more often in extraadrenal or familial forms. 


\section{Malignant PHEO}

Malignant PHEO is confirmed if metastasis of chromaffin tissue is found at unusual locations. Large tumors, extra-adrenal or familial forms carry a higher risk of malignancy. The clinical course in malignant forms is variable, with 5 -year survival rates of $50 \%$.

There is no convincingly effective mode of treatment in malignant PHEOs. Surgical removal of all tumor tissue should be the preferred approach. Conservative therapy with $\alpha$-blockers may control BP and symptoms. Shrinkage of the tumor mass has been reported with the inhibitor of catecholamine synthesis, metyrosine. Treat- ment with ${ }^{131}$ I-MIBG or chemotherapy with cyclophosphamide, vincristine and dacarbazine deteriorate quality of life and may lead to complete remission only in the minority of patients [10]. High doses of ${ }^{131}$ I-MIBG have been shown to improve long-term survival [26] but apparently control studies are missing. Skeletal metastasis may respond to irradiation or radiofrequency ablation $[4,10]$.

\section{Acknowledgement}

This study was partly supported by a research project of the Ministry of Education of Czech Republic (M.S.M.) Nos. 0021620817, 0021620808, 0021620807.

\section{References}

1 McNeil AR, Blok BH, Koelmeyer TD, et al: Phaeochromocytoma discovered during coronial autopsies in Sydney, Melbourne and Auckland. Aust NZ J Med 2000;30:648652.

-2 Štrauch B, Zelinka T, Hampf M, Bernhardt R, Widimský J Jr: Prevalence of primary hyperaldosteronism in moderate to severe hypertension in the Central Europe region. J Hum Hypertens 2003;17:349-352.

-3 Manger WM, Eisenhofer G: Pheochromocytoma: diagnosis and management update. Curr Hypertens Rep 2004;6:477-484.

4 Kaplan NM: Clinical Hypertension. Philadelphia, Lippincott Williams \& Wilkins, 2006, pp 1-518.

5 Zelinka T, Štrauch B, Pecen L, Widimský J Jr: Diurnal blood pressure variation in pheochromocytoma, primary aldosteronism and Cushing's syndrome. J Hum Hypertens 2004;18:107-111.

6 Zelinka T, Widimský J Jr, Weisserová J: Diminished circadian blood pressure rhythm in patients with asymptomatic normotensive pheochromocytoma. Physiol Res 2001;50: 631-634.

7 Kikuya M, Hozawa T, Ohkubo T, Tsuji I, Michimata M, Matsubara M, et al: Prognostic significance of blood pressure and heart rate variabilities. The Ohasama study. Hypertension 2000;36:901-906.

-8 Zelinka T, Štrauch B, Petrák O, Holaj R, Vranková A, Weisserová H, Pacák K, Widimský J Jr: Increased blood pressure variability in pheochromocytoma compared to essential hypertension patients. J Hypertens 2005;23:2033-2039.
Neumann HP, Bausch B, McWhinney SR, et al for the Freiburg-Warsaw-Columbus Pheochromocytoma Study Group: Germline mutations in nonsyndromic pheochromocytoma. N Engl J Med 2002;346:1459-1466.

10 Lenders JWM, Eisenhofer G, Mannelli M, Pacák K: Pheochromocytoma. Lancet 2005; 366:665-675.

11 Amar L, Bertherat J, Baudin E, Ajzenberg C, Bressacde Paillerets B, Chabre O, Chamontin B, Delemer B, Giraud S, Murat A, Niccoli-Sire P, Richard S, Rohmer V, Sadoul JL, Strompf L, Schlumberger M, Bertagna X, Plouin PF, Jeunemaitre X, Gimenez-Roqueplo AP: Genetic testing in pheochromocytoma or functional paraganglioma. J Clin Oncol 2005;23:8812-8818.

12 Eisenhofer G, Keiser H, Friberg P, et al: Plasma metanephrines are markers of pheochromocytoma produced by catechol-O-methyltransferase within tumors. J Clin Endocrinol Metab 1998;83:2175-2185.

13 Lenders JW, Pacák K, Walther MM, et al: Biochemical diagnosis of pheochromocytoma: which test is best? JAMA 2002;287:14271434.

14 Goldstein DS, Eisenhofer G, Flynn JA, et al: Diagnosis and localisation of pheochromocytoma. Hypertension 2004;43:907-910.

15 Bravo EL, Tagle R: Pheochromocytoma: state of the art and future prospects. Endocr Rev 2003;24:539-553.

16 Kudva YC, Sawka AM, Young WF Jr, et al: The laboratory diagnosis of adrenal pheochromocytoma: the Mayo Clinic experience. J Clin Endocrinol Metab 2003;88:45334539.

$\checkmark 17$ Bravo EL, Tarazi RC, Fouad FM, Vidt DG, Gifford RW Jr: Clonidine suppression test: a useful aid in the diagnosis of pheochromocytoma. N Engl J Med 1981;305:623-626.
18 Eisenhofer G, Goldstein DS, Walther MM, et al: Biochemical diagnosis of pheochromocytoma: how to distinguish true- from falsepositive results. J Clin Endocrinol Metab 2003;88:2656-2666.

19 Mukherjee JJ, Peppercorn PD, Reznek RH, et al: Pheochromocytoma: effect of non-ionic contrast medium in CT on circulating catecholamine levels. Radiology 1997;202:227231.

20 Pacák K, Eisenhofer G, Carrasquillo JA, Chen CC, LiST, Goldstein DS: 6- $\left[{ }^{18} \mathrm{~F}\right]$ fluorodopamine positron emission tomographic scanning for diagnostic localisation of pheochromocytoma. Hypertension 2001;38:6-8.

21 Ilias I, Pacák K: Current approaches and recommended algorithm for the diagnostic localisation of pheochromocytoma. J Clin Endocrinol Metab 2004;89:479-491.

22 Prys-Roberts C: Pheochromocytoma - recent progress in its management. Br J Anaesth 2000;85:44-57.

23 Janetschek G, Finkenstdt G, Gasser R, et al: Laparoscopic surgery for pheochromocytoma: adrenalectomy, partial resection, excision of paragangliomas. J Urol 1998;160: 330-334.

-24 Sprung J, O’Hara JF Jr, Gill IS, Abdelmalak B, Sarnaik A, Bravo EL: Anesthetic aspects of laparoscopic and open adrenalectomy for pheochromocytoma. Urology 2000;55:339343.

25 Plouin PF, Chatellier G, Fofol I, Corvol P: Tumour recurrence and hypertension persistence after successful pheochromocytoma operation. Hypertension 1997;29:1133-39.

26 Rose B, Matthay KK, Price D, et al: Highdose ${ }^{131}$ I-MIBG therapy for 12 patients with malignant pheochromocytoma. Cancer 2003;98:239-248. 